Article

\title{
Effect of the (Nd,Dy)-Double Doping on the Structural Properties of Ceria
}

\author{
Cristina Artini 1,2,* , Lara Gigli ${ }^{3}$ D , Maria Maddalena Carnasciali ${ }^{1,4}$ and Marcella Pani ${ }^{1,5}$ \\ 1 Department of Chemistry and Industrial Chemistry, University of Genova, Via Dodecaneso 31, \\ 16146 Genova, Italy \\ 2 Institute of Condensed Matter Chemistry and Technologies for Energy, National Research Council, \\ CNR-ICMATE, Via De Marini 6, 16149 Genova, Italy \\ 3 Elettra-Sincrotrone Trieste S.C.p.A., ss 14, km 163.5, 34149 Basovizza, Italy \\ 4 INSTM, Genova Research Unit, Via Dodecaneso 31, 16146 Genova, Italy \\ 5 CNR-SPIN, Corso Perrone 24, 16152 Genova, Italy \\ * Correspondence: artini@chimica.unige.it; Tel.: +39-010-3536082
}

Received: 12 June 2019; Accepted: 23 July 2019; Published: 26 July 2019

\begin{abstract}
The crystallographic properties of the $\mathrm{Ce}_{1-x}\left(\mathrm{Nd}_{0.63} \mathrm{Dy}_{0.37}\right)_{x} \mathrm{O}_{2-x / 2}$ system $(0 \leq x \leq 0.6)$ were studied by means of synchrotron powder X-ray diffraction and compared to the ones of Sm-doped ceria. The aim of this work was to investigate the effect of substituting $\mathrm{Sm}^{3+}$ by a mixture of a smaller and a larger ion that ensures a more pronounced $\mathrm{Ce}^{4+} /$ dopant size mismatch while having the same average ionic size as $\mathrm{Sm}^{3+}$. Two main findings came to light: (a) the compositional region of the $\mathrm{CeO}_{2}$-based solid solution widens up to $x$ ranging between 0.4 and 0.5 , and (b) the cell parameter is larger than the one of Sm-doped ceria at each composition. Both effects are expected to play a significant role on the ionic conductivity of the material. The results are discussed in terms of disorder and cation-vacancy association.
\end{abstract}

Keywords: solid oxide fuel cells; doped ceria; powder X-ray diffraction; synchrotron radiation

\section{Introduction}

Rare Earth (RE)-doped ceria systems form a thoroughly studied class of ceramic materials displaying interesting values of ionic conductivity, which make them attractive solid electrolytes to be used in solid oxide fuel cells (SOFCs) working in the intermediate temperature range (673-973 K) [1]. $\mathrm{Ce}_{0.9} \mathrm{Gd}_{0.1} \mathrm{O}_{1.95}$ and $\mathrm{Ce}_{0.8} \mathrm{Sm}_{0.2} \mathrm{O}_{1.90}$, for instance, present a remarkable ionic conductivity value of $10^{-2}$ $\mathrm{S} \mathrm{cm}^{-1}$ at $773 \mathrm{~K}[2,3]$, which allows us to significantly lower the cell operating temperature with respect to SOFCs by employing $\mathrm{Y}_{2} \mathrm{O}_{3}$-doped $\mathrm{ZrO}_{2}$ as an electrolyte, and, thus, to prolong the cell lifetime.

The mechanism of ionic conductivity in doped ceria is strictly connected to the structural properties of the material, such as defects association to the extent of the $\mathrm{CeO}_{2}$-based solid solution. For this reason, the crystallographic approach is not separate from the investigation of physical properties. On the contrary, it is fundamental in drawing guidelines aimed at designing efficient materials. Ionic conductivity in doped ceria implies the diffusion of $\mathrm{O}^{2-}$ anions through the vacancies induced by the random partial substitution of $\mathrm{Ce}^{4+}$ by a trivalent ion. The mechanism optimally works if concentration and size of the doping ion fall within the proper range: if the dimension of the guest ion is sufficiently close to the one of $\mathrm{Ce}^{4+}$, the fluorite-related cubic structure of $\mathrm{CeO}_{2}$ (hereafter named $\mathrm{F}$, space group $\mathbf{F} \boldsymbol{m} \overline{\mathbf{3}} m$, Ce coordination number: 8) tolerates the $\mathrm{Ce}^{4+}$ substitution, at least in terms of long range order and up to a certain degree, and oxygen vacancies can freely move through the lattice. Nevertheless, maximum values of ionic conductivity are observed at $x$ (in $\mathrm{Ce}_{1-x} \mathrm{RE}_{x} \mathrm{O}_{2-x / 2}$ ) 0.10-0.15, which, generally, corresponds to a composition far from the upper compositional limit of the phase. 
The cited maximum occurs well within the F range, because with increasing $x$, an increasing portion of the whole vacancies amount is blocked at fixed positions and no more able to move, since it becomes part of C-structured nano-domains and microdomains [4]. Recently, reverse Monte Carlo modeling indicated that, in Sm-doped ceria already at $x=0.05$, the descriptions of average and local structure do not coincide, which suggests that, even at such a small doping level, the local environment around $\mathrm{Ce}^{4+}$ undergoes a distortion with respect to the $\mathrm{F}$ structure due to the formation of randomly oriented C-type droplets [5]. The C cubic structure (space group I $a \overline{3}, \mathrm{RE}$ coordination number: 6 ) consists of a superstructure of $\mathrm{F}$, which presents a cell parameter that, for $\mathrm{RE} \equiv \mathrm{Sm}$ and $\mathrm{Gd}$, is roughly doubled with respect to the one of $\mathrm{CeO}_{2}$.

Beyond the $\mathrm{F}$ upper compositional limit, two different scenarios appear, depending on the $\mathrm{Ce}^{4+} / \mathrm{RE}^{3+}$ size mismatch: if it exceeds $10 \%$, the two-phase $(\mathrm{F}+\mathrm{C})$ field results to be stable, while, below this threshold, a hybrid $\mathrm{F} / \mathrm{C}$ phase occurs [6]. In agreement with these remarks, Sm-doped and Gd-doped ceria, which are the most efficient systems in terms of ionic conductivity, crystallize in the hybrid atomic arrangement [7,8]. Lu-doped ceria, on the contrary, presents the two-phase $(\mathrm{F}+\mathrm{C})$ field when more than $\sim 40 \% \mathrm{Ce}^{4+}$ atoms are replaced by $\mathrm{Lu}^{3+}[9,10]$. The occurrence of the hybrid $(\mathrm{H})$ phase can be recognized in diffraction patterns through the absence of splitting between the peaks common to $\mathrm{F}$ and $\mathrm{C}$, accompanied by an increase in intensity of the superstructure peaks with increasing $x$. Further signs marking the $\mathrm{F} \rightarrow \mathrm{H}$ transition are the abrupt discontinuity in the coefficient of thermal expansion [11,12] and in the formation temperature of the oxides [13]. The nature of $\mathrm{H}$, which is widely discussed in previous papers $[1,7,8,10,11,14,15]$, consists of a solid solution where the F-related $\mathrm{CeO}_{2}$ phase behaves as a matrix, and $\mathrm{C}$-structured $\mathrm{RE}_{2} \mathrm{O}_{3}$ microdomains act as guests (while, in the $\mathrm{F}$ region, guests are represented by the randomly placed $\mathrm{RE}^{3+}$ ions).

As previously mentioned, the Sm-doped system is one of the most efficient ceria-based materials to be used as electrolytes [16]. Nevertheless, even if dimensional issues definitely play a role, the reason for this behavior is non-trivial, since it cannot be just attributed to the reduced lattice strain due to the $\mathrm{Ce}^{4+} / \mathrm{Sm}^{3+}$ size resemblance: Nd-doped ceria, for instance, shows similarly high ionic conductivity values, in spite of a remarkably larger strain caused by the non-negligible $\mathrm{Ce}^{4+} / \mathrm{Nd}^{3+}$ size mismatch [17]. Similarly, films of doped ceria exhibit a higher ionic conductivity when doped by a $\mathrm{Nd} / \mathrm{Sm}$ mixture than by the sole $\mathrm{Sm}$, due to the increased tensile strain brought about by the presence of $\mathrm{Nd}$ [18]. Starting from this point, the present work is intended to study the structural features of a system, $\mathrm{Ce}_{1-x}\left(\mathrm{Nd}_{0.63} \mathrm{Dy}_{0.37}\right)_{x} \mathrm{O}_{2-x / 2}$, where the most promising properties of both $\mathrm{Nd}$-doped and $\mathrm{Sm}$-doped ceria in terms of ionic conductivity are associated. The reasonableness of this choice is also testified by results reported in Reference [19], which indicate a value of ionic conductivity of $2.2 \times 10^{-2}$ $\mathrm{S} / \mathrm{cm}$ at $873 \mathrm{~K}$ for $\mathrm{Ce}_{0.8} \mathrm{Nd}_{0.1} \mathrm{Dy}_{0.1} \mathrm{O}_{1.85}$.

The $\mathrm{Ce}_{1-x}\left(\mathrm{Nd}_{0.63} \mathrm{Dy}_{0.37}\right)_{x} \mathrm{O}_{2-x / 2}$ doubly doped system combines an average dopant ionic size very close to the one of $\mathrm{Sm}^{3+}$, and a significant lattice strain due to the presence of a larger $\left(\mathrm{Nd}^{3+}\right)$ and a smaller $\left(\mathrm{Dy}^{3+}\right)$ ion with respect to $\mathrm{Sm}^{3+}$. The mean size of $\mathrm{Sm}^{3+}$ is reproduced by using an $\mathrm{Nd} / \mathrm{Dy}$ mixture in the 0.63:0.37 atomic ratio, given that the $\mathrm{Nd}^{3+}$ and the $\mathrm{Dy}^{3+}$ ionic sizes (CN8) are $1.109 \AA$ and $1.027 \AA$ [20], respectively. The cited mixture provides an average dopant size of $1.079 \AA$, which exactly corresponds to the ionic radius reported for $\mathrm{Sm}^{3+}(\mathrm{CN} 8)$ [20]. Co-doping of ceria has been very widely studied in the past few years [21], since it has long been known as an effective method to enhance the ionic conductivity performance of ceria [22]. This approach was, in fact, generally predicted to favor higher values of ionic conductivity as compared to singly-doped systems, due to the hindering effect exerted by the presence of different doping ions on the growth of large C-structured clusters [23] and to the increased mobility of charge carriers. The issue is debated [24], but the effect of suppression of the oxygen vacancies local ordering is expected to lead to higher values of ionic conductivity, which is experimentally observed in the previously mentioned $\mathrm{Nd} / \mathrm{Dy}-[19]$, and also in Gd/Y- [25], Gd/Sm- [25-27], La/Sm- [28], Sm/Nd- [29], Nd/Gd- [30], Pr/Nd- [31], Pr/Gd- [32], Er/Gd- [33], $\mathrm{Pr} / \mathrm{La}-[34], \mathrm{La} / \mathrm{Dy}-[35]$ doped $\mathrm{CeO}_{2}$. In this work, a detailed study of the way the contemporary 
presence of two different doping ions enlarges the compositional extent of the F phase by hindering the vacancies association, and how it affects the main structural parameters of doped ceria, is presented.

\section{Results}

A series of six samples with nominal $x=0,0.1,0.2,0.3,0.4,0.5$, and 0.6 , belonging to the $\mathrm{Ce}_{1-x}\left(\mathrm{Nd}_{0.63} \mathrm{Dy}_{0.37}\right)_{x} \mathrm{O}_{2-x / 2}$ system, was investigated. The lanthanide content of all the oxides was checked by scanning electron microscopy coupled to energy-dispersive system (SEM-EDS), and the experimental $x$ values are collected in Table 1 . It can be observed that they are very close to the nominal ones. Relying on this outcome, for each sample, the stoichiometric cationic amount was implemented into the structural model, and not allowed to vary in Rietveld refinement cycles. Figure 1 reports SEM microphotographs taken on the surface of the pellet of sample NdDy20 (a) and NdDy60 (b): A larger particle size is revealed by increasing the dopant content.

Table 1. Values of $x$ in $\mathrm{Ce}_{1-x}\left(\mathrm{Nd}_{0.63} \mathrm{Dy}_{0.37}\right)_{x} \mathrm{O}_{2-x / 2}$ resulting from EDS, and Rietveld agreement factors.

\begin{tabular}{cccc}
\hline Sample Name & $x$ & $\mathbf{R}_{\mathbf{B}}{ }^{\mathbf{a}}$ & $\chi^{\mathbf{2}} \mathbf{b}$ \\
\hline NdDy10 & $0.09(1)$ & 2.27 & 1.70 \\
NdDy20 & $0.19(2)$ & 1.81 & 1.80 \\
NdDy30 & $0.29(7)$ & 2.55 & 1.73 \\
NdDy40 & $0.37(6)$ & 2.74 & 1.73 \\
NdDy50 & $0.47(9)$ & 9.73 & 1.45 \\
NdDy60 & $0.58(5)$ & 9.79 & 2.73 \\
\hline \multicolumn{5}{c}{${ }^{a} R_{B}=\frac{\sum_{k}\left|I_{k, o b s}-I_{k, \text { call }}\right|}{\sum_{k}\left|I_{k, o b s}\right|} ;{ }^{b} \chi^{2}=\left(\frac{R_{w w p}}{R_{e x p}}\right)^{2}$}
\end{tabular}
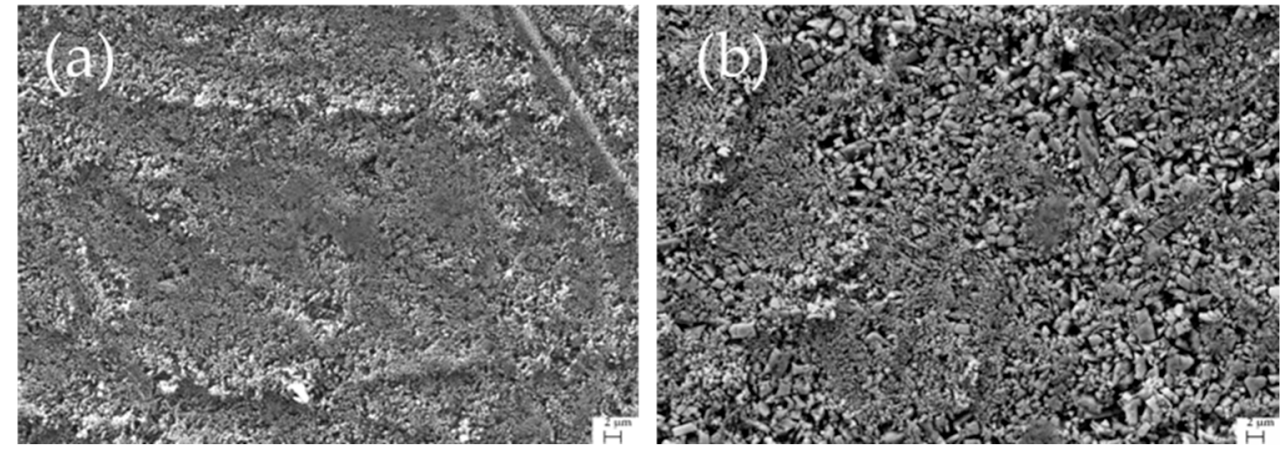

Figure 1. SEM microphotographs taken by backscattered electrons on the surface of pellets of sample (a) NdDy20 and (b) NdDy60.

Since, for $0.1 \leq x \leq 0.4$, only peaks related to the F structure appear, while superstructure peaks occur starting from $x=0.5$, diffraction patterns were refined, according to two structural models, namely to $\mathrm{F}(0.1 \leq x \leq 0.4)$ and $\mathrm{H}(x=0.5$ and 0.6$)$. Structural models $\mathrm{F}, \mathrm{H}$, and $\mathrm{C}$ are reported as Supplementary Materials in Table S1. While, in F, only two atomic positions are occupied (the $4 a$ site by the rare earth and the $8 \mathrm{c}$ by $\mathrm{O}$ ), in $\mathrm{C}$, the rare earth site is split into two distinct positions. The hybrid structure $\mathrm{H}$ represents a transcription of $\mathrm{F}$ positions in terms of $I a \overline{3}$, i.e., the space group that properly describes the $C$ structure. As a consequence, structural parameters, which, in the $F m \overline{3} m$ space group, were constrained by symmetry, are no more fixed in $I a \overline{3}$, and become a sensitive mark of the $\mathrm{F} / \mathrm{H}$ transition occurring under the action of the $\mathrm{C}$ microdomains growth. Moreover, an additional position with respect to $C$ is needed in $16 c$ to place the excess oxygen atoms. Therefore, the $\mathrm{H}$ structure shares characters of both $\mathrm{F}$ and $\mathrm{C}$ without being identical to any one of them: rather, it conveniently describes the gradual and continuous transition from $\mathrm{F}$ to $\mathrm{C}$ by increasing the doping ion content.

The peak profile matching was done for each pattern using the pseudo-Voigt function. The background was optimized by linear interpolation of a set of $\sim 70$ points chosen from the 
experimental pattern. Individual displacement parameters $B$ were refined for each $\mathrm{Ce} / \mathrm{Nd} / \mathrm{Dy}$ site. In the $\mathrm{H}$ model, the same refined $\mathrm{B}$ was attributed to both oxygen atoms.

Diffraction patterns of samples with $x$ ranging between 0.1 and 0.4 were also refined, according to the $\mathrm{H}$ structural model, in order to study the behavior of parameters sensitive to the $\mathrm{F} / \mathrm{C}$ transition, such as, for example, the RE1 $x$ position and the $\mathrm{O} 2$ occupancy factor. In Figure 2, the Rietveld refinement plot of sample NdDy20 is reported as a representative example.

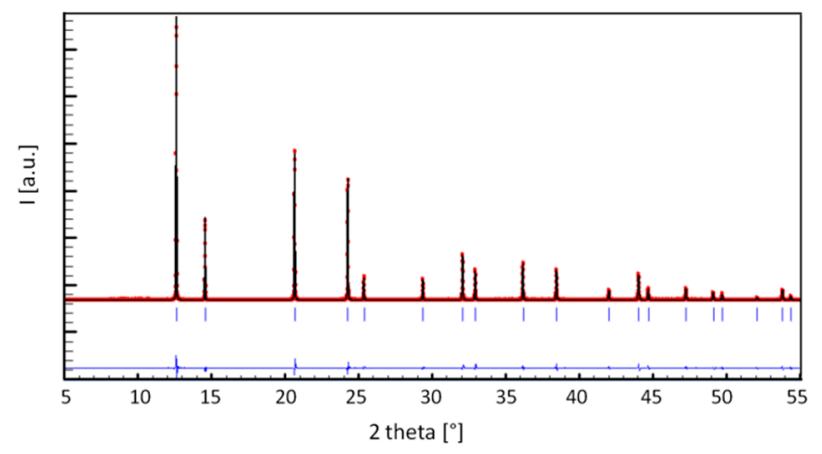

Figure 2. Rietveld refinement plot of sample NdDy20. The dotted (red) and the continuous (black) lines are the experimental and the calculated diffraction pattern, respectively. The lower line is the difference curve, and vertical bars show the calculated positions of Bragg peaks.

The analysis of X-ray diffraction results suggests two main observations: if compared to the $\mathrm{Sm}$-doped system, (a) the compositional extent of the F region is wider and, (b) at each composition, the cell parameter is larger.

With reference to item (a), diffraction patterns reported in Figure 3a indicate that the most lightly doped sample displaying superstructure peaks is NdDy50, which suggests that the $\mathrm{F} / \mathrm{H}$ transition is located at $x$ ranging between 0.4 and 0.5. In Figure $3 b$, the diffractogram collected on $\mathrm{Ce}_{0.6} \mathrm{Sm}_{0.4} \mathrm{O}_{1.8}$ is shown as a term of comparison: peaks belonging to $\mathrm{H}$ are clearly visible. A further structural parameter marking the $\mathrm{F} / \mathrm{H}$ transition is the RE1 $x$ position: when $\mathrm{C}$ microdomains dispersed within the $\mathrm{F}$ matrix are large enough to be revealed by $\mathrm{X}$-rays, this parameter significantly moves from $\frac{1}{4}$, i.e., from the value imposed by symmetry in $F m \overline{3} m$, toward $\sim 0.28$, which is the value typical of the RE1 $x$ position of the $24 d$ site in $I a \overline{3}$. Figure 4 , reporting the trend of the RE1 $x$ position vs. the RE content for both the Nd/Dy- and the Sm-doped ceria [8], clearly suggests that, in the former system, the F/H transition occurs at higher dopant content with respect to the latter, which confirms the previously described evidence.

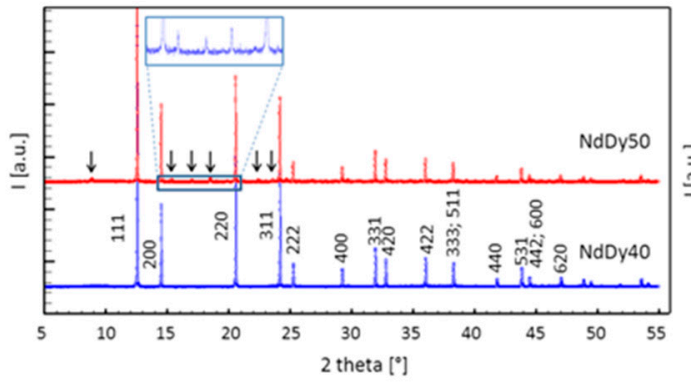

(a)

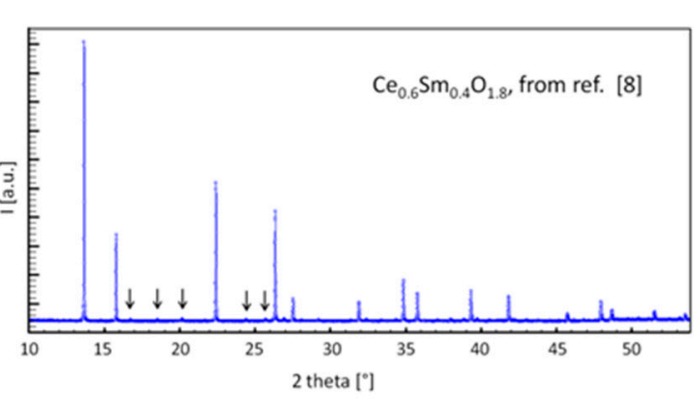

(b)

Figure 3. Diffraction patterns of (a) NdDy40 and NdDy50 samples and (b) sample $\mathrm{Ce}_{0.6} \mathrm{Sm}_{0.4} \mathrm{O}_{1.8}$ [8]. Arrows indicate the presence of superstructure peaks, with an enlarged view between $14^{\circ}$ and $21^{\circ}$. In (a) Miller indices of peaks belonging to the F phase are reported within the diffraction pattern of NdDy 40. 


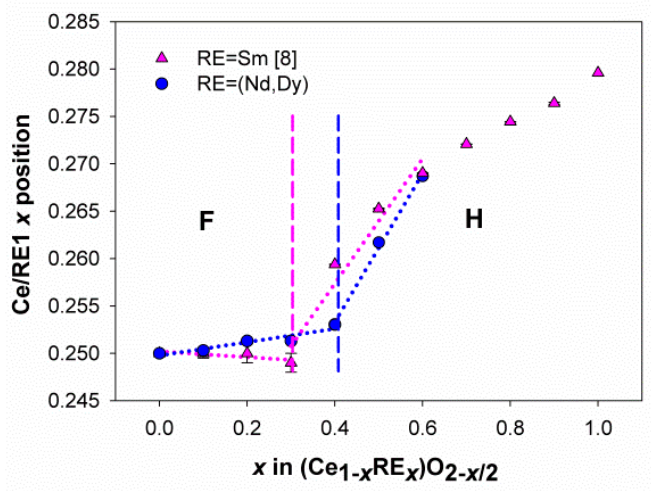

Figure 4. Trend of the RE1 $x$ position in the Nd/Dy- and Sm-doped systems. Data of Sm are taken from Reference [8]. Error bars are sometimes hidden by data markers. Dotted lines are regression lines fitting data within the $\mathrm{F}$ and the $\mathrm{H}$ region. The vertical dashed lines approximately indicate the position of the $\mathrm{F} / \mathrm{H}$ transition.

Figure 5 shows the behavior of the lattice parameter of both Sm- [8] and Nd/Dy-doped ceria as a function of the dopant content. In both systems, the trend is not linear, due to the not constant atomic content of the cell due to the oxygen loss taking place with increasing $x$, as discussed in References $[8,10]$.

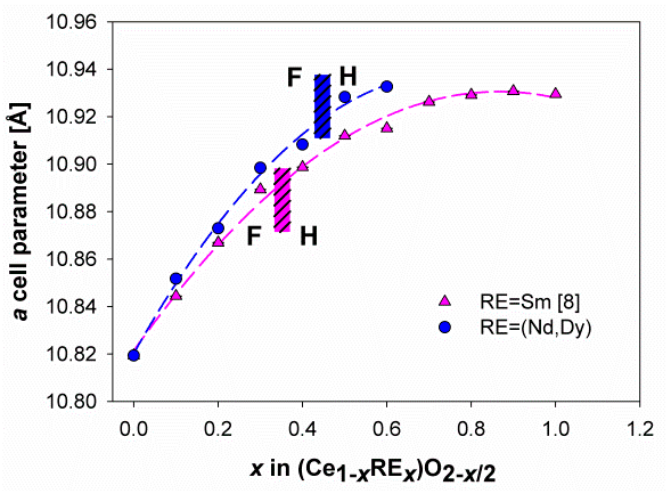

Figure 5. Trend of the lattice parameter of the $\mathrm{Nd} / \mathrm{Dy}$ - and Sm-doped systems as a function of the doping ion(s) content. Data of Sm are taken from Reference [8]. Error bars are hidden by data markers. Data are fitted by second order polynomial functions.

A further hint toward a change in the structural properties of the Nd/Dy-doped systems comes from the analysis of the full width at half maximum (FWHM) of the most intense structure peak. In Figure 6, reporting the previously mentioned parameter as a function of the $\mathrm{Nd} / \mathrm{Dy}$ content, a progressive rise can be observed up to $x=0.4$, which suggests a disorder increase taking place within the F phase by increasing the doping ion content. The strain effect brought about by the insertion of both doping ions results in a broadening of the peak, which grows until the F matrix tolerates the entrance into the structure of randomly located guests. The roughly constant FWHM value revealed at higher $x$, on the contrary, is fully compatible with the growth of $C$ microdomains, which incorporate an increasing amount of vacancies by subtracting them from the F-based solid solution. 


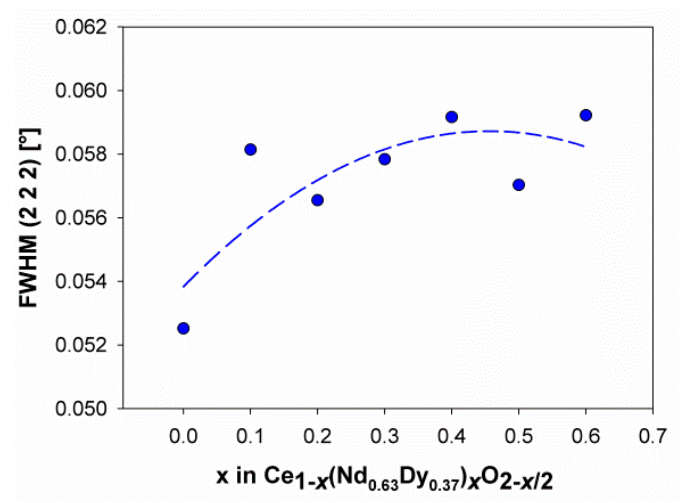

Figure 6. FWHM values of the most intense structure peak as a function of the $\mathrm{Nd} / \mathrm{Dy}$ content.

The dashed line is a second order polynomial function fitting experimental data.

\section{Discussion}

The two main results derived from the experimental results previously described, namely the widening of the $\mathrm{F}$ compositional region and the increase of the cell parameter with respect to the Sm-doped system, lead to the conclusion that the $\left(\mathrm{Nd}_{0.63} \mathrm{Dy}_{0.37}\right)$ mixture does not behave like the isodimensional $\mathrm{Sm}^{3+}$. On the contrary, it seems to mimic a larger ion. Doping by a larger ion causes not only-as expected-an increase in the cell parameter, but also a shift of the $\mathrm{F}$ limit toward higher $\mathrm{x}$ values, such as $x=0.4$ and $x=0.6$ for $\mathrm{RE} \equiv \mathrm{Nd}^{3+}$ and $\mathrm{La}^{3+}$ [36], respectively. This phenomenon takes place for two main reasons: (a) the stability of the $\mathrm{F}$ and the $\mathrm{C}$ phase depend on the size resemblance of $\mathrm{Ce}^{4+}$ and $\mathrm{RE}^{3+}$ both with coordination number 8 (which rules $\mathrm{F}$ ) and 6 (which rules $\mathrm{H}$ ) (therefore, the actual extent of both phases is driven by the interplay of the $\mathrm{Ce}^{4+} / \mathrm{RE}^{3+}$ size similarity with both coordination numbers) [1], and (b) a larger atom more effectively counterbalances the creation of vacancies within $\mathrm{F}$, which tend to shrink the lattice.

The reason why a lanthanide mixture mimics a larger ion is most likely the disorder effect caused by the presence of different doping ions, which partially hinders the maturation of $C$ microdomains and, ultimately, makes the F phase more tolerant toward vacancies. This hypothesis is corroborated by the results of theoretical studies, which predicts a restraint in the growth of $C$ clusters in co-doped systems [23].

The effect exerted by $\mathrm{Nd} / \mathrm{Dy}$ co-doping on the lattice parameter is very unique as well, since results reported in the literature show different data depending on the system considered. The $\mathrm{Ce}_{1-x} \mathrm{Sm}_{x / 2}$ $\mathrm{Nd}_{x / 2} \mathrm{O}_{2-x / 2}$ system, for instance, is claimed to show a linear trend of the lattice parameter as a function of $x$, and this behavior is interpreted as the mark for a reduced attraction vacancy/dopant. This, consequently, leads to the observed inhibition of the $\mathrm{C}$ microdomains growth and the consequent higher ionic conductivity [29]. On the contrary, this is not the case of the $\mathrm{Nd} / \mathrm{Dy}$-doped system, which shows a nonlinear trend of the lattice parameter (see Figure 5), as expected for systems where the total atomic content is not kept constant with changing $x$. Nevertheless, even in this case, an enlargement of the $\mathrm{F}$ region is observed, as previously described.

The higher value of the cell parameter observed at each composition with respect to the Sm-doped system, seems to suggest that the lattice size is mainly driven by the larger of the two doping ions, rather than by the average ionic dimension. This result likely deals with the issue related to cation-vacancy association [1]. This is a very complicated item, which is primarily ruled by two factors including the stronger repulsion of vacancies by tetravalent $\mathrm{Ce}^{4+}$ rather than by the trivalent dopant(s), and the preference of smaller ions toward lower coordination numbers. In spite of the somehow contradictory results of EXAFS measurements, a general tendency is observed, consisting in the preferred association of vacancies to the first-neighbor site of dopants smaller than, and to the second-neighbor site of dopants larger than $\mathrm{Gd}^{3+}$ [37]. This conclusion is in good agreement with the work by Ye et al. [38], which, through a theoretical study, predict the first-neighbor location of vacancies in $\mathrm{Yb}_{-}, \mathrm{Y}_{-}$, and Dy-doped ceria and the second-neighbor one in systems containing larger doping ions, such as $\mathrm{Gd}^{3+}$ 
and $\mathrm{Sm}^{3+}$. A similar conclusion was also obtained by Zhang et al. [39], with reference to systems doped with ions going from $\mathrm{Sm}^{3+}$ to $\mathrm{Tm}^{3+}$.

The cell parameter of doped ceria is bound to the cation-vacancy association, since it is mainly determined by the size of the doping ion, which randomly enters the F matrix. Ions trapped into $C$ clusters virtually do not affect the lattice size. The preferential association of vacancies to smaller rather than to larger ions provides a possible explanation for the observed discrepancy between the cell size of $\mathrm{Sm}$ - and of $\mathrm{Nd} / \mathrm{Dy}$-doped ceria, notwithstanding the identical average ionic radius.

\section{Materials and Methods}

\subsection{Synthesis}

Six compositions belonging to the $\mathrm{Ce}_{1-x}\left(\mathrm{Nd}_{0.63} \mathrm{Dy}_{0.37}\right)_{x} \mathrm{O}_{2-x / 2}$ system with nominal $x=0,0.1,0.2$, $0.3,0.4,0.5$, and 0.6 were synthesized by oxalates co-precipitation, as previously described $[40,41]$. $\mathrm{The} \mathrm{Nd} / \mathrm{Dy}$ ratio was chosen, so that the mean ionic size of the lanthanides mixture reproduces the one of $\mathrm{Sm}^{3+}$ [CN:8], i.e., the most efficient dopant for ceria in terms of ionic conductivity. Stoichiometric amounts of $\mathrm{Ce}$ (Johnson Matthey ALPHA $99.99 \%$ wt.), $\mathrm{Nd}_{2} \mathrm{O}_{3}$, and $\mathrm{Dy}_{2} \mathrm{O}_{3}$ were separately dissolved in $\mathrm{HCl}(13 \%$ vol.). Mixing of the two solutions followed. Afterward, the precipitation of the mixed $\mathrm{Ce} / \mathrm{Nd} / \mathrm{Dy}$ oxalate was accomplished by adding a solution of oxalic acid in large excess. Oxalates were then filtered, washed, dried for $12 \mathrm{~h}$, and, subsequently, thermally treated at $1373 \mathrm{~K}$ in air for four days to obtain the mixed oxides. Samples are named NdDy10, NdDy20, and so on, according to the nominal $(\mathrm{Nd}, \mathrm{Dy})$ atomic percent with respect to the total rare earth's content.

\subsection{Scanning Electron Microscopy-Energy-Dispersive System (SEM-EDS)}

Scanning electron microscopy with field emission gun and energy-dispersive system (FE-SEM-EDS, Zeiss SUPRA 40 VP-30-51 scanning electron microscope, equipped with a high sensitivity "InLens" secondary electron detector, and an EDS microanalysis INCA Suite Version 4.09, Oxford Instruments, Abingdon-on-Thames, UK) was employed to check the overall rare earth content of all the samples. Pellets of pressed powders were coated by a graphite layer and analyzed at a working distance of $15 \mathrm{~mm}$, with acceleration voltage $20 \mathrm{kV}$. EDS analyses were carried out on at least four points for each sample.

\subsection{Synchrotron X-Ray Powder Diffraction}

Room temperature diffraction patterns of all the samples were collected at the powder diffraction beamline (MCX) at Elettra synchrotron radiation facility located in Trieste, Italy, by a Huber 4-axes $\mathrm{X}$-ray diffractometer equipped with a fast scintillator detector. Specimens were placed in borosilicate capillary tubes with inner diameter of $0.5 \mathrm{~mm}$, and rotated at a speed of $180 \mathrm{rpm}$. Acquisitions were done in the angular range $5^{\circ} \leq 2 \theta \leq 55^{\circ}$ with step $0.01^{\circ}$, counting time $1 \mathrm{~s}$, with the incident beam energy set at $18 \mathrm{keV}$.

The FullProf suite [42] was used to refine structural models by the Rietveld method.

\section{Conclusions}

A crystallographic investigation was performed by powder synchrotron $\mathrm{X}$-ray diffraction on several samples belonging to the $\mathrm{Ce}_{1-x}\left(\mathrm{Nd}_{0.63} \mathrm{Dy}_{0.37}\right)_{x} \mathrm{O}_{2-x / 2}$ system with the aim to study the effect of the substitution of $\mathrm{Sm}^{3+}$ by a mixture of a larger and a smaller rare earth ion providing an average ionic radius very close to the ionic radius of $\mathrm{Sm}^{3+}$. The idea underlying this work is that co-doping is expected to enhance the ionic conductivity of the system by inhibiting the $C$ clusters' growth.

Two main findings were revealed: with respect to Sm-doped ceria, (a) the compositional extent of the $\mathrm{CeO}_{2}$-based solid solution widens, and (b) the cell parameter is larger at each composition. These data suggest that the $\left(\mathrm{Nd}_{0.63} \mathrm{Dy}_{0.37}\right)$ mixture acts as a larger ion with respect to $\mathrm{Sm}^{3+}$. The former observation can find an explanation invoking the disorder increase caused by the contemporary 
presence of two different doping ions, which hinders the growth of the C-structured microdomains. The latter is ascribed to the preference of vacancies toward association with the first-neighbor site of doping ions smaller than $\mathrm{Gd}^{3+}$, which, in the present case, translates into a preferred association of vacancies with $\mathrm{Dy}^{3+}$ rather than with $\mathrm{Nd}^{3+}$. This effect tends to subtract the smaller doping ion $\left(\mathrm{Dy}^{3+}\right)$ from the $\mathrm{CeO}_{2}$-based solid solution, with the larger ion $\left(\mathrm{Nd}^{3+}\right)$, consequently, exerting a stronger effect on the cell size. The inhibition of the $\mathrm{C}$ microdomains maturation is a positive precondition for obtaining high values of ionic conductivity.

Supplementary Materials: The following are available online at http://www.mdpi.com/2304-6740/7/8/94/s1, Table S1: Hybrid structural model compared to the $\mathrm{F}$ structure typical of $\mathrm{CeO}_{2}$ and the $\mathrm{C}$ structure typical of sesquioxides of heavy rare earths.

Author Contributions: Conceptualization, C.A. and M.P. Investigation, L.G., M.M.C., and M.P. Writing-original draft, C.A. Writing-review \& editing, C.A., L.G., M.M.C., and M.P.

Funding: This research received no external funding.

Acknowledgments: Anna Fois is acknowledged for the preliminary data treatment.

Conflicts of Interest: The authors declare no conflict of interest.

\section{References}

1. Artini, C. RE-doped ceria systems and their performance as solid electrolytes: A puzzling tangle of structural issues at the average and local scale. Inorg. Chem. 2018, 57, 13047-13062. [CrossRef] [PubMed]

2. Steele, B.C.H. Appraisal of $\mathrm{Ce}_{1-y} \mathrm{Gd}_{y} \mathrm{O}_{2-y / 2}$ electrolytes for IT-SOFC operation at $500{ }^{\circ} \mathrm{C}$. Solid State Ion. 2000, 129, 95-110. [CrossRef]

3. Presto, S.; Artini, C.; Pani, M.; Carnasciali, M.M.; Massardo, S.; Viviani, M. Ionic conductivity and local structural features in $\mathrm{Ce}_{1-x} \mathrm{Sm}_{x} \mathrm{O}_{2-x / 2}$. Phys. Chem. Chem. Phys. 2018, 20, 28338-28345. [CrossRef] [PubMed]

4. Coduri, M.; Scavini, M.; Pani, M.; Carnasciali, M.M.; Klein, H.; Artini, C. From nano to microcrystals: Effect of different synthetic pathways on defects architecture in heavily Gd-doped ceria. Phys. Chem. Chem. Phys. 2017, 19, 11612-11630. [CrossRef] [PubMed]

5. Kraynis, O.; Timoshenko, J.; Huang, J.; Singh, H.; Wachtel, E.; Frenkel, A.I.; Lubomirsky, I. Modeling strain distribution at the atomic level in doped ceria films with extended X-ray absorption fine structure spectroscopy. Inorg. Chem. 2019, 58, 7527-7536. [CrossRef] [PubMed]

6. Artini, C.; Carnasciali, M.M.; Costa, G.A.; Plaisier, J.R.; Pani, M. A novel method for the evaluation of the Rare Earth (RE) coordination number in RE-doped ceria through Raman spectroscopy. Solid State Ion. 2017, 311, 90-97. [CrossRef]

7. Artini, C.; Costa, G.A.; Pani, M.; Lausi, A.; Plaisier, J. Structural characterization of the $\mathrm{CeO}_{2} / \mathrm{Gd}_{2} \mathrm{O}_{3}$ mixed system by synchrotron X-ray diffraction. J. Solid State Chem. 2012, 190, 24-28. [CrossRef]

8. Artini, C.; Pani, M.; Carnasciali, M.M.; Buscaglia, M.T.; Plaisier, J.; Costa, G.A. Structural features of Sm- and Gd-doped ceria studied by synchrotron X-ray diffraction and $\mu$-Raman spectroscopy. Inorg. Chem. 2015, 54, 4126-4137. [CrossRef] [PubMed]

9. Artini, C.; Joseph, B.; Costa, G.A.; Pani, M. Crystallographic properties of Lu-doped ceria, $\mathrm{Ce}_{1-x} \mathrm{Lu}_{x} \mathrm{O}_{2-x / 2}$, at pressures up to $7 \mathrm{GPa}$. Solid State Ion. 2018, 320, 152-158. [CrossRef]

10. Artini, C.; Pani, M.; Carnasciali, M.M.; Plaisier, J.R.; Costa, G.A. Lu-, Sm- and Gd-doped ceria: A comparative approach to their structural properties. Inorg. Chem. 2016, 55, 10567-10579. [CrossRef]

11. Artini, C.; Pani, M.; Lausi, A.; Masini, R.; Costa, G.A. High temperature structural study of Gd-doped ceria by synchrotron X-ray diffraction (673 K $\leq \mathrm{T} \leq 1073 \mathrm{~K})$. Inorg. Chem. 2014, 53, 10140-10149. [CrossRef] [PubMed]

12. Artini, C.; Carnasciali, M.M.; Viviani, M.; Presto, S.; Plaisier, J.R.; Costa, G.A.; Pani, M. Structural properties of Sm-doped ceria electrolytes at the fuel cell operating temperatures. Solid State Ion. 2018, 315, 85-91. [CrossRef]

13. Artini, C.; Nelli, I.; Pani, M.; Costa, G.A.; Caratto, V.; Locardi, F. Thermal decomposition of Ce-Sm and Ce-Lu mixed oxalates: Influence of the Sm- and Lu-doped ceria structure. Thermochimica Acta 2017, 651, 100-107. [CrossRef]

14. Scavini, M.; Coduri, M.; Allieta, M.; Brunelli, M.; Ferrero, C. Probing complex disorder in $\mathrm{Ce}_{1-x} \mathrm{Gd}_{x} \mathrm{O}_{2-x / 2}$ using the pair distribution function analysis. Chem. Mater. 2012, 24, 1338-1345. [CrossRef] 
15. Coduri, M.; Masala, P.; Allieta, M.; Peral, I.; Brunelli, M.; Biffi, C.A.; Scavini, M. Phase transformations in the $\mathrm{CeO}_{2}-\mathrm{Sm}_{2} \mathrm{O}_{3}$ system: A multiscale powder diffraction investigation. Inorg. Chem. 2018, 57, 879-891. [CrossRef]

16. Kuharuangrong, S. Ionic conductivity of Sm, Gd, Dy- and Er-doped ceria. J. Power Sources 2007, 171, 506-510. [CrossRef]

17. Omar, S.; Wachsman, E.D.; Jones, J.L.; Nino, J.C. Crystal structure-ionic conductivity relationships in doped ceria. J. Am. Ceram. Soc. 2009, 92, 2674-2681. [CrossRef]

18. Pandiyan, A.; Rajagopalan, R.; Hassan Tanveer, W.; Yu, W.; Cha, S.W.; Krishna Moorthy, S.B. Scalable lattice-strain in preferentially oriented acceptor-doped ceria oxide film and its impact on oxygen ion transport kinetics. Electrochem. Acta 2018, 264, 203-215. [CrossRef]

19. Bhabu, K.A.; Theertagiri, J.; Madhavan, J.; Balu, T.; Rajasekaran, T.R. Superior oxide ion conductivity of novel acceptor doped cerium oxide electrolytes for intermediate-temperature solid oxide fuel cell applications. J. Phys. Chem. C 2016, 120, 18452-18461. [CrossRef]

20. Shannon, R.D. Revised effective ionic radii and systematic studies of interatomic distances in halides and chalcogenides. Acta Cryst. 1976, A32, 751-767. [CrossRef]

21. Dell'Agli, G.; Spiridigliozzi, L.; Pansini, M.; Accardo, G.; Yoon, S.P.; Frattini, D. Effect of the carbonate environment on morphology and sintering behaviour of variously co-doped (Ca, Sr, Er, Pr) Samarium-doped ceria in co-precipitation/hydrothermal synthesis. Ceram. Int. 2018, 44, 17935-17944. [CrossRef]

22. Van Herle, J.; Seneviratne, D.; Mc Evoy, A.J. Lanthanide co-doping of solid electrolytes: AC conductivity behaviour. J. Eur. Ceram. Soc. 1999, 19, 837-841. [CrossRef]

23. Ou, D.R.; Ye, F.; Mori, T. Defect clustering and local ordering in rare earth co-doped ceria. Phys. Chem. Chem. Phys. 2011, 13, 9554-9560. [CrossRef] [PubMed]

24. Burbano, M.; Nadin, S.; Marrocchelli, D.; Salanne, M.; Watson, G.M. Ceria co-doping: Synergistic or average effect? Phys. Chem. Chem. Phys. 2014, 16, 8320-8331. [CrossRef] [PubMed]

25. Zayac, W.; Molenda, J. Electrical conductivity of doubly doped ceria. Solid State Ion. 2008, 179, $154-158$.

26. Kim, N.; Kim, B.H.; Lee, D. Effect of co-dopant addition on properties of gadolinia-doped ceria electrolyte. J. Power Sources 2000, 90, 139-143. [CrossRef]

27. Coles-Aldridge, A.V.; Baker, R.T. Ionic conductivity in multiply substituted ceria-based electrolytes. Solid State Ion. 2018, 316, 9-19. [CrossRef]

28. Gupta, M.; Shirbhate, S.; Ojha, P.; Acharya, S. Processing and conductivity behavior of La, Sm, Fe singly and double doped ceria: As electrolytes for IT-SOFC. Solid State Ion. 2018, 320, 199-209. [CrossRef]

29. Omar, S.; Wachsman, E.; Nino, J. Higher conductivity $\mathrm{Sm}^{3+}$ and $\mathrm{Nd}^{3+}$ co-doped ceria-based electrolyte materials. Solid State Ion. 2008, 178, 1890-1897. [CrossRef]

30. Arabaci, A.; Altınçekiç, T.G.; Der, M.; Öksüzömer, M.A.F. Preparation and properties of ceramic electrolytes in the $\mathrm{Nd}$ and Gd Co-doped ceria systems prepared by polyol method. J. Alloy Compd. 2019, 792, 1141-1149. [CrossRef]

31. Babu, A.S.; Bauri, R. Rare earth co-doped nanocrystalline ceria eletrolytes for intermediate temperature solid oxide fuel cells (IT-SOFC). ECS Trans. 2013, 57, 1115-1123. [CrossRef]

32. Arabaci, A. Synthesis and characterization of $\mathrm{Pr} / \mathrm{Gd}$ co-doped ceria by using the citric acid-nitrate combustion method. Solid State Ion. 2018, 326, 69-76. [CrossRef]

33. Arabaci, A.; Sariboğa, V.; Őksüzőmer, M.A.F. Er and Gd co-doped ceria-based electrolyte materials for IT-SOFCs prepared by the cellulose-templating method. Met. Mater. Trans. A 2014, 45, 5259-5269. [CrossRef]

34. Madhuri, C.; Venkataramana, K.; Nurhayati, A.; Vishnuvardhan Reddy, C. Effect of $\mathrm{La}^{3+}$ and $\operatorname{Pr}^{3+}$ co-doping on structural, thermal and electrical properties of ceria ceramics as solid electrolytes for IT-SOFC applications. Curr. Appl. Phys. 2018, 18, 1134-1142. [CrossRef]

35. Venkataramana, K.; Madhuri, C.; Madhusudan, C.; Suresh Reddy, Y.; Bhikshamaiah, G.; Vishnuvardhan Reddy, C. Investigation on $\mathrm{La}^{3+}$ and $\mathrm{Dy}^{3+}$ co-doped ceria ceramics with an optimized average atomic number of dopants for electrolytes in IT-SOFCs. Ceram. Int. 2018, 44, 6300-6310. [CrossRef]

36. Horlait, D.; Claparède, L.; Clavier, N.; Szencnekt, S.; Dacheux, N.; Ravaux, J.; Podor, R. Stability and structural evolution of $\mathrm{Ce}^{\mathrm{IV}}{ }_{1-x} \mathrm{Ln}^{\mathrm{III}}{ }_{x} \mathrm{O}_{2-x / 2}$ solid solutions: A coupled $\mu$-Raman/XRD approach. Inorg. Chem. 2011, 50, 150-161. [CrossRef] [PubMed]

37. Minervini, L.; Zacate, M.O.; Grimes, R.W. Defect cluster formation in $\mathrm{M}_{2} \mathrm{O}_{3}$-doped $\mathrm{CeO}_{2}$. Solid State Ion. 1999, 116, 339-349. [CrossRef] 
38. Ye, F.; Mori, T.; Ou, D.R.; Cormack, A.N. Dopant type dependency of domain development in rare earth-doped ceria: An explanation by computer simulation of defect clusters. Solid State Ion. 2009, 180, 1127-1132. [CrossRef]

39. Zhang, L.; Meng, J.; Yao, F.; Zhang, W.; Liu, X.; Meng, J.; Zhang, H. Insight into the Mechanism of the Ionic Conductivity for Ln-Doped Ceria ( $\mathrm{Ln}=\mathrm{La}, \mathrm{Pr}, \mathrm{Nd}, \mathrm{Pm}, \mathrm{Sm}, \mathrm{Gd}, \mathrm{Tb}, \mathrm{Dy}, \mathrm{Ho}, \mathrm{Er}$, and Tm) through First-Principles Calculation. Inorg. Chem. 2018, 57, 12690-12696. [CrossRef] [PubMed]

40. Artini, C.; Costa, G.A.; Carnasciali, M.M.; Masini, R. Stability fields and structural properties of intra rare earths perovskites. J. Alloy Compd. 2010, 494, 336-339. [CrossRef]

41. Artini, C.; Costa, G.A.; Masini, R. Study of the formation temperature of mixed $\mathrm{LaREO}_{3}(\mathrm{RE} \equiv \mathrm{Dy}, \mathrm{Ho}, \mathrm{Er}, \mathrm{Tm}$, $\mathrm{Yb}, \mathrm{Lu}$ ) and $\mathrm{NdGdO}_{3}$ oxides. J. Anal. Calorim. 2011, 103, 17-21. [CrossRef]

42. Rodriguez-Carvajal, J. Recent advances in magnetic structure determination by neutron powder diffraction. Phys. B Condens. Matter 1993, 192, 55-69. [CrossRef]

(C) 2019 by the authors. Licensee MDPI, Basel, Switzerland. This article is an open access article distributed under the terms and conditions of the Creative Commons Attribution (CC BY) license (http://creativecommons.org/licenses/by/4.0/). 